\title{
La construcción del discurso político apocalipticista del Vade Mecum in Tribulatione de Juan de Rocatallada en la Castilla de Juan II
}

\author{
The construction of the apocalyptical political discourse in the Vade Mecum in \\ tribulatione by Juan de Rocatallada during Juan II Castile.
}

\author{
Israel Sanmartín \\ israel.sanmartin@usc.es \\ Universidad de Santiago de Compostela, España
}

Recepción: 20 Agosto 2020

Aprobación: 07 Octubre 2020

Publicación: 04 Enero 2021

Cita sugerida: Sanmartín, I. (2021). La construcción del discurso político apocalipticista del Vade Mecum in Tribulatione de Juan de Rocatallada en la Castilla de Juan II. Trabajos y Comunicaciones, (53), e137. https://doi.org/10.24215/23468971e137
Resumen: El presente trabajo analizará el Vade Mecum in Tribulatione de Juan de Rocatallada. El relato que este construye en su obra apocalipcista cobra una dimensión, que a su vez genera una historia política que en su época se convirtió en discurso político. Con el fin de desenmarañar el mismo se analizarán los elementos de la construcción narrativa, así como las dimensiones reales y "maravillosas" de la obra.

Palabras clave: Apocaliptismo, Discurso, Rocatallada.

\begin{abstract}
In this paper the Vade Mecum in Tribulatione by Juan de Rocatallada shall be analyzed. The narration he builds in this apocalyptic work took a political dimension which in turn gave birth to a political history that during the XVth century generated a political discourse. To achieve our goal, to unravel said discourse, the elements of the narrative construction as well as the real and "marvelous" dimensions of the aforementioned work will be analyzed.
\end{abstract}

Keywords: Apocalypticism, Discourse, Rocatallada.

Este artículo es una investigación centrada en el Vade Mecum in Tribulatione de Juan de Rocatallada. Dicho texto es originario del siglo XIV francés, pero fue difundido en la Castilla del siglo XV. Ahí se modernizaron las fechas y se transcribieron diferentes manuscritos de los que conservamos cinco. Uno de ellos, el perteneciente a la Biblioteca Capitular de Oviedo es el que manejaremos en este trabajo. Se trata de una versión inédita que hemos transcrito y utilizado. El «Vade Mecum in Tribulacione» es un manual para sobrevivir a las turbulencias que vendrán como consecuencia de la crisis política y eclesiástica de su tiempo. Rocatallada compone un relato donde el apocalipticismo adquiere una dimensión política. Eso es lo que intentaremos desentrañar. Para ello identificaremos el desarrollo de una "historia política" propia de su época que convertirá en discurso político.

Para trabajar con esa historia política y con ese discurso político analizaremos los diferentes elementos de la construcción narrativa apocalipticista. Paralelamente a esto, nos detendremos en todo lo relativo al texto en su dimensión real/ficcional, y recurriremos al análisis de acontecimientos, tanto en su dimensión real 
como "maravillosa". Lo que vamos a estudiar es la ruptura que representa el apocalipsis, en donde hay ciertos acontecimientos, sobre todo vinculados a lo maravilloso que toman autonomía y parece que son capaces de provocar un fin definitivo disruptivo y romper ese tiempo de espera eterno hacia el Juicio Final característico del cristianismo.

Para realizar todo esto comenzaremos explicando qué es «Vade Mecum in Tribulacione», seguiremos mostrando el contenido del libro y sus versiones hispanas. Una vez terminada esta parte del trabajo, comenzaremos con el análisis del discurso político apocalíptico, para lo que estudiaremos, sus elementos, sus estratos y su configuración temporal, para terminar, relacionándolo con el milenarismo y el fin del mundo.

\section{1 ¿Qué es el Vade Mecum in Tribulatione?}

El «Vade Mecum in Tribulacione» es un manual escatológico escrito por Juan de Rocatallada (o Rupescissa), que es uno de los autores apocalípticos más destacados del siglo XIV. El «Vade Mecum in Tribulacione» circuló en los siglos XIV y XV por diferentes países del Occidente Medieval. Al menos, cuarenta manuscritos han llegado hasta nosotros. Rupescissa nace en Aurillac e ingresa en los frailes menores en 1332. La fecha de su muerte está datada en 1365 o 1366, dependiendo de los autores. Después de estudiar teología en la Universidad de Toulousee, sufre una serie de visiones que le hacen proyectar la llegada del anticristo.

J. Rocatallada decide registrar en papel las profecías y visiones con cierta regularidad. Como consecuencia, en el año 1344 ingresa en la cárcel por sus escritos, en los que defiende la doctrina franciscana y sus visiones del anticristo. Esos dos elementos programáticos los acompaña de ataques constantes al papado de Aviñón. Su actitud le lleva a peregrinar por varias cárceles de la zona. Entra y sale de prisión mientas defiende sus teorías frente al Papa. Según los especialistas, muere el 17 de Julio de 1366 (Kaup, M., 2017, p. 11) por una herida mal curada en una pierna.

J. Rocatallada escribe textos apocalípticos de carácter teológico y político conectados con su época. Escribió unos treinta trabajos de los que siete han llegado hasta hoy. En su obra Liber Ostensor (1360-64) pone de manifiesto su joaquinismo y se autoproclama elegido para llevar a cabo profecías en las que especula con cuestiones francesas y peninsulares. En el 1349 escribe el Liber Secretorum Eventum y en el 1356 el Vademecum in Tribulatione.

El contexto histórico en el que escribe su obra tiene una atmósfera apocalíptica. La guerra, los cismas religiosos y el contexto escatológico sobre el fin del mundo son los acontecimientos próximos a su escritura. El Papado de Aviñón entre 1309 y 1377 y la guerra de los cien años, así como la defensa de los reyes de Francia, en especial de los Capetos (Felipe V, Carlos IV, Felipe II y Juan II) son algunos de los eventos que marcan su obra.

El «Vade Mecum in Tribulacione» fue escrito en diciembre de 1356 (Bignami-Odier, J., 1952). Es el libro más difundido e influyente de Rupescissa (Reeves, M., 1969). Fue elaborado en latín y fue traducido en diferentes idiomas vernáculos como el francés, inglés, italiano, alemán, checo, catalán y castellano. En el caso francés, tenemos tres traducciones independientes. Y existe versión en aljamiado realizada por mozárabes (Kaup, M., 2017, p. 19). En el libro el autor describe trece años horror y dureza hasta 1370, causados por los anticristos occidentales y orientales y por un emperador herético, acompañados por un pseudo mesías. Rupescissa intenta construir un mundo con forma franciscana donde ellos dominen el estadio final. También es un escrito para que puedan triunfar frente a los males el verdadero Papa y su asistente el Emperador francésromano para llevar al triunfo del cristianismo. Es decir, es un texto para prepararse ante la crisis de la guerra de los cien años, del Papado y de los problemas en el reinado de Juan II (en las versiones hispanas). Es un libro que tiene la intención de la restauración franciscana del Papa. El objetivo de todo esto es preparar a la cristiandad para los problemas inminentes y las catástrofes que se aproximaban. 


\section{El contenido del «Vade Mecum in Tribulatione»}

Como hemos señalado, Rupescissa empieza su descripción del final de los tiempos en la primera intención anunciando que será antes del año 1370, cuando el mundo estará bajo el poder del Papa romano. Las precondiciones para eso serían la vuelta a la vida de cristo y de los apóstoles (Kaup, M., 2017, p. 5).

En primer lugar, tenemos a la «epístola prefacialis», que tiene una dedicatoria a un monje franciscano que tiene por nombre Pierre Périer. Escribe como alguien que conoce los textos proféticos joaquinitas siendo un texto breve que lo llama «Vademecum» porque es una guía para los futuros peligros. Su carácter predictivo radica en que se encuentra escrito para variar el curso de los acontecimientos. Después tenemos veinte intenciones que hablan sobre el final de los tiempos. La primera intención sostiene que el mundo estará antes de 1370 en manos del Obispo de Roma; la segunda que la condición de esto es que Papas y clérigos tienen que regresar a la forma de vida de Cristo y los apóstoles; la tercera que los clérigos se desvían de la buena vida; la cuarta que la curia dejará Aviñón antes de julio de 1362. La quinta y sexta que en los eventos entre 1357-1360 aparecerá un anticristo asociado a toda una serie de catástrofes. Además, se hace referencia a la situación de Francia en 1359 y a la lucha de España e Italia contra los infieles. La séptima intención recuerda que la clerecía debe de volver a la pobreza; la octava que entre 1362 y 1365 habrá una persecución de la iglesia por el anticristo que aparecerá en 1361. La Novena, décima, decimoprimera y decimosegunda harían mención a la restauración del Papa. La decimotercera y decimocuarta son los problemas de las órdenes enriquecidas; la decimoquinta la destrucción de ciudades (Aurillac y su conexión concreta con Pierre Périer). La Decimosexta muestra siete remedios. Decimoséptima y Decimoctava muestran una scriptura luciferarum desde Satán y el Anticristo. Se referencia a Gog y Magog y la batalla que se dará en el año 2065. La Vigésima es la justificación del comienzo del reinado de los mil años. En esa cronología, 1365 sería el año central de los eventos escatológicos a partir del libro de Daniel. Se muestran tres profecías no canónicas del «Liber Ostensor»: a) "Prophetia Cum Necatur Flos Ursi" que deja el año 1360 como el principio de cinco años preparatorios para un momento terrorífico, y señala que el 15 de julio será el fin de la lucha entre los cardenales de Aviñón; y b) y c) las profecías "Prophetia Neapolitiana" y "Prophetia Beneventana". (Kaup, M., 2017, p.10)

En el epílogo, señala que escribe no como un profeta sino como alguien que lo hace para entender los textos proféticos. Dice que esto es necesario para sobrevivir en las tribulaciones. Escribe el trabajo para enviar a la iglesia y que le hagan caso.

\section{El «VAde Mecum in Tribulatione» en sus Versiones hispanas}

$\mathrm{El}$ «Vade Mecum in Tribulacione» está escrito originalmente en 1356 y tuvo mucho éxito tanto en el siglo XIV como en el XV. El libro está estructurado en veinte capítulos (diecinueve en las versiones castellanas) donde se hacen eco del próximo apocalipsis que tendrá lugar entre 1360 y 1365 . Después de esos años tendrán lugar el inicio de un milenio de paz. El contexto de producción señala los acontecimientos más importantes sobre las tribulaciones que tendrían lugar en la época. Se difunde en Castilla en el siglo XV en su primera mitad. Hay dos menciones a J. Rocatallada en los poemas de Alfonso Álvarez de Villasandino en 1417 y en el Cancionero de Baena en 1432; esto puede verse en F. Gómez Redondo (2002, p. 3089-3094).

El contexto en el que se difunde es el del reinado de Juan II - que es analizado por J. Guadalajara Medina (2004) - , caracterizado por intrigas y crisis entre nobles y monarca. En muchas de las versiones del «Vade Mecum» que circularon en el siglo XV las cronologías fueron modernizadas, y Castilla no es una excepción. Así, en las versiones castellanas transmite contenidos proféticos revitalizados o modernizados. Las cronologías se modernizan desde 1360-65 a 1460-65. En Castilla, diferentes poetas y autores asocian a J. Rocatallada con Merlín. La fecha de redacción de los textos castellanos sería para el caso del manuscrito de la B.R.H.A el año 1412 mientras que, para el manuscrito ovetense, el 1456 (o en todo caso antes del 1460). También hay una versión catalana para la que se mantiene la cronología sin modificar. 
El contexto en el que se engarzan los textos hispanos del «Vade Mecum» se corresponden al reinado de Juan II, durante cuyo mandato aparecen muchos textos con esta matriz apocalíptica. El rey castellano se enfrentaba a su minoría de edad y a las posteriores tensiones con sus primos y sobre todo con D. Álvaro de Luna, como analizó J. M. Calderón Ortega (1998). Esa situación mostraba la debilidad de reino y nos proporciona la explicación para entender la proliferación de guerras e intrigas entre los diferentes grupos de la Corte y los reyes peninsulares, J. M. ${ }^{a}$ Monsalvo Antón (2010) tiene más datos a este respecto. Por ese motivo, tenemos el «Libro de la consolación de España» o el «Libro de las tribulaciones» de Fray Lope Fernández de Minaya, además de opúsculos visionarios relativos al Anticristo, como los de Vicente Ferrer en su venida a Castilla de 1411, las traducciones de los textos de Juan Unay, Martín Martínez de Ampiés o el «Libro de Conocimiento del fin del Mundo»; F. Ramires (2012) ofrece una perspectiva más amplia.

En la península circuló un texto que consta de tres partes diferenciadas: a) «epístola prefacialis»; b) el fin de los tiempos de las veinte intenciones; c) epílogo. Tenemos cinco versiones del texto en los Reinos Hispánicos: a) La de la biblioteca de la Real Academia de la Historia (B.R. A. H.) MS Cortes 9-11-1/2176 que se llama Libro de las tribulaciones; b) la de la Biblioteca Capitular de Oviedo Ms 18 de título "Ven amigo e non e partes de mi en tiempos de tribulaciones"; c) la de la Biblioteca Universidad de Salamanca MS 1877 que se denomina "Buen amigo non te apartes de mi en el tiempo de las tribulaciones"; d) la de la Biblioteca Inguimbertine de Carpentras MS 336 que se intitula "Ve Ab mi entribulación”; y, e) BNE MS 5305 la versión en castellano aljemiado. El año de redacción parece que oscila entre 1412 y 1456. Puede que el autor fuera Pierre Perier o Diego de Moxena, según Isaac Vázquez Janeiro. Se cita a Requena, que puede ser una localidad de Valencia, pero también puede ser de Palencia; J. Guadalajara Medina (1996, pp. 353-375) analiza este punto. Para el análisis del texto en este trabajo usaremos la versión ovetense, que está inédita.

El libro está introducido por una carta, que es una declaración de intenciones y advertencias morales y de cómo se han verificado algunos vaticinios. En la versión de Oviedo, en la carta se incluye una mención a P. Périer, médico minorita a quien le solicitó la profecía y que lo visitó en diferentes ocasiones cuando estaba prisionero. Está dirigida a P. Périer, que era franciscano y físico. J. Rocatallada habla en la carta inicial que Pierre le preguntó en una de sus visitas a la cárcel si podía predecir el futuro y él lo hizo. Tanto la versión de Oviedo como la de la B.R.A.H. está modernizadas las fechas en cien años. La de Oviedo tiene Incipit y la otra no. Estas fechas estarían rectificadas porque él aún no era conocido en Castilla. El «Vade Mecum» no circuló. En la versión ovetense, el nombre de J. Rocatallada es citado en el Incipit. Además, el autor era conocido por el Cancionero de Baena y se asimilaba a un profeta como Merlín. Como decíamos, en su versión castellana el libro moderniza las fechas en cien años. De tal forma, el año 1360/65 pasa a ser el año 1460/65. El libro muestra unos sucesos catastróficos que no se habían completado. Es, por tanto, una modificación de una profecía no cumplida.

En Aragón, J. Rocatallada era más conocido. Francisco de Eximenis menciona él en la Vida de Jesucristo. Hay una tendencia que defiende que Rocatallada podría ser un autor catalán. Incluso algunos autores lo citan como Juan de Peratallada, que es una localidad de Gerona.

En cuanto al contenido, el texto tiene una primera parte en la que habla del triunfo de la fe católica sobre el Papa, la clerecía y el papado de Aviñón. La segunda parte habla del caos que sucederá entre 1460-65. En ese momento los "cazadores serán cazados" y habrá un anticristo oriental que anidará en la tierra entre grandes catástrofes naturales (diluvios, etc.) y la destrucción la Iglesia. La tercera parte es una parte que hace relación a la historia. Así se muestran en el texto las peleas entre Francia e Inglaterra. También se habla de que España conquistará a los moros. Anuncia, además, que habrá un Padre Santo que vivirá 9,5 años y un Emperador (que reinará diez años) que será el rey de Francia que destruirá el mal y arreglará la Iglesia. Ambos nombrarán un Rey que conquistará Jerusalén. En la cuarta parte, el texto se refiere al hambre y las malas situaciones que tendrán que soportar los frailes mendicantes que no cumplen con los preceptos de la Orden. La quinta parte aborda los remedios sobre las tribulaciones. Como sobrevivir a terremotos o la necesidad de guardar la comida en cuevas cinco o diez años antes de que lleguen las tribulaciones. La sexta parte se significa en favor del año 
del milenio y el Juicio Final. Por último, en la parte final se manifiesta como alguien que no es un profeta y sí una persona que es capaz de encontrar el verdadero significado de los textos.

\section{El discurso político apocalíptico en el Vade Mecum in Tribulatione}

Rocatallada es un apocalipticista tradicional, desordenado y contradictorio, con la particularidad de que él no se cree un profeta sino un descubridor de los secretos de los textos bíblicos. Lo apocalíptico, en un sentido general, es sinónimo de escatológico. Está vinculado a la relación de los sucesos que pondrán fin a la existencia de este mundo y los acontecimientos que seguirán dentro de una cronología predeterminada. Lo apocalíptico político es un género literario y un modo de pensar. Siguiendo esas ideas, podemos establecer que el paradigma apocalíptico político de J. Rocatallada contiene los siguientes elementos:

a) El mundo está abocado a un proceso de destrucción final: “e sabed que por la presion del rey de Françia non seran mas pocas batallas que fueron fasta en antes seran mas e mas granes, e diran las gentes 'paz, paz' e non sera tienpo de paz" (de Rocatallada, J. 1356, p. 321v). En este caso, acaba en una destrucción que llevaría a la paz, pero hay casos que se señalan con peor fin:

“(...) que sin detemiento han de matar las gentes, e esto han mas de ser que el omme puede cuydar, e han de ser aguas de luvias mas que nunca fueron desde el tienpo de Noe aca. E otrosi han de ser grandes fanbres e gran mengua de viandas qual aun non fue vista. En tal guisa que por las dichas tribulaçiones e afliçiones e pestilençias han de morir e peresçer la mayor parte desta generaçion e gente mala desconoscida a Dios que agora bive" (de Rocatallada, J., 1356, p.320v)

b) La destrucción del mundo será precedida por una serie de catástrofes cósmicas. Pueden ser pestes:

"la grand pestilençia que han de foyr a los montes e esconderse asi commo las palomas en los penedos escondidos, e que esta tribulaçion durara çinco annos. Por ende que los que son cuerdos e sabios deven fazer provision en los montes e en las cuevas, e en los lograres çiertos e escondidos poner provision de havas e de otras legunbres, e de carrnes" (de Rocallada, J., 1356, p. 321v).

Y también hace referencia a hambrunas:

"Otrosi seran atorrmentados de grande e grave pena e fanbre que en breve tienpo e çedo ha de venir e de otras pestilençias e tribulaçiones que son declaradas en el quinto capitulo deste libro. Otrosi avran de ser apremiados e emendados de los sus exçesos e torrnados a dicha e justa manera de bevir" (de Rocatallada, J., 1356, p. 324v)

c) El tiempo del mundo aparece dividido en periodos cuyo desarrollo está predeterminado "e que esta tribulaçion durara çinco annos" (de Rocatallada, J., 1356, p. 325v)

d) La catástrofe final del mundo estará seguida por la aparición de un mundo u orden nuevo del que participarán todos los que hayan tenido buen comportamiento. Por un lado, ese mundo recental está vinculado al Anticristo:

"Esta es la primera resureçion en la qual el que oviere parte sera bienaventurado, e en aquestos la segunda muerte non avra poderio. E por ende paresçe en el dicho de Sant Juan que en el tienpo de la muerte del Antechristo los dichos martiles han de reçuçitar, asy commo dicho es” (de Rocatallada, J., 1356, p. 326v)

Por otro lado, está vinculado a personajes concretos, a eclesiásticos y grandes hombres que no cumplían con los preceptos verdaderos del cristianismo:

"Otrosi seran atorrmentados de grande e grave pena e fanbre que en breve tienpo e çedo ha de venir e de otras pestilençias e tribulaçiones que son declaradas en el quinto capitulo deste libro. Otrosi avran de ser apremiados e emendados de los sus exçesos e torrnados a dicha e justa manera de bevir” (de Rocatallada, J., 1356, p. 324v)

e) Los que tengan mala conducta tendrán castigo eterno. "El quinseno capitulo nos es demostrado e declarado en commo muchas çibdades del mundo onrradas han de ser perseguidas", escribe J. Rocatallada (1356, p. 325r). Y apuntala que "el primer remedio es que dize Sant Mateo en el evangelio 
a los XXIIII capitulos, donde dize e demuestra que non queramos ser enganados creyendo en cosa que diga nin faga el Antechristo nin ninguno que sea que su parte tenga” (1356, p. 325v).

A esto hay que añadirle algunos elementos contextuales propios del discurso apocalipticista:

a) Es literatura que tiene su origen en el seno de conmociones políticas y religiosas. «El Vade Mecum in Tribulatione» está vinculado a Aviñón en Francia y a la época atribulada de Juan II en Castilla. Eso lo reboza de situaciones de catástrofes que sitúa en un arco temporal de cinco años, entre 1460 y 1465.

b) Tiene una dimensión más allá de lo histórico porque está proyectada a un futuro. "Devedes saber que los dichos rectores e perlados antes que lleguemos al anno de mill e quatroçientos e setenta annos, queriendo o non queriendo, por muchos torrmentos e grandes tribulaçiones, seran torrnados a la manera de bivir de los apostoles, e por esto podran ensennar a los infieles asi commo pertenesçe" (1356, p. 319v), argumenta Rocatallada.

c) Está revelada por Dios a videntes o mediante sueños, arrebatos o a través de símbolos crípticos. El Anticristo es un actor fundamental en las revelaciones:

"la segunda maravilla es que antes que lleguemos al anno de mill e quatroçientos e sesenta e çinco annos que aparesçera publicamente en tierra de Oriente un Antichristo, e los diçipulos verrnan en tierra de Iherusalem e pedricaran publicamente por convertir la gente a la creençia deste Antechristo, e mostraran e faran grandes maravillas e sennales por poderio del Antechristo e del espiritu malino" (de Rocatallada, J., 1356, p. 320v)

En otro sentido también nos encontramos con Jesucristo: "Ihesu Christo despraçara e porrna fuera de su tenplo e Iglesia a los corrutos e menguados e simonaticos saçerdotes e a sus gentes, nin querran que le administren nin ofrescan sacrefiçio" (de Rocatallada, J., 1356, p. 323v). Pero también mediante el mismo Dios en compañía: "otrosi Dios por los sobredichos papa e carrdenal reparan e remenbraran las relgas de los evangelios segunt que los apostoles bivieron e los clerigos deven bevir" (de Rocatallada, J., 1356. P. 323v). O también por Dios solo: "la sesta cosa es que en las iglesias e altares e en los otros logares de oraçion por muchas partes del mundo seran destruydas e estragadas, e menguara e desfalleçera el sacrifiçio e serviçio de Dios” (de Rocatallada, J., 1356, p. 321r).

d) La finalidad del texto es universal y exhorta al creyente, pero también al Papa y las jerarquías de la Iglesia, denunciando sus abusos y condenándola para que hagan frente a la crisis universal (Lozano Escribano, J. y Anaya Acebes, L., 2002, pp. 26-27). Por ejemplo: "el Papa e los cardenales, patriarcas, arçobispos e todas las otras presonas (sic) eclesiasticas han de ser reduçidas e torrnadas a un modo e manera de bivir muy acabado" (de Rocatallada, J., 1356, p. 320r). Y también: "otrosi seran atorrmentados de grande e grave pena e fanbre que en breve tienpo e çedo ha de venir e de otras pestilençias e tribulaçiones que son declaradas en el quinto capitulo deste libro. Otrosi avran de ser apremiados e emendados de los sus exçesos e torrnados a dicha e justa manera de bevir" (de Rocatallada, J., 1356, p.324v)

En otro sentido, está preñado de mitologemas:

a) Nacimiento de bestias y monstruos mitológicos: "e quando las dos bestias que el Antechristo uviere e Satanas fuere atado en fondo de los abismos, onde yasera preso por mill annos asi commo dize Sant Iohan en el viçesimo capitulo del Libro de las Revelaçiones" (de Rocatallada, J., 1356, p. 326r). En algunas ocasiones, tales bestias tienen vínculos con personas concretas:

"en el tienpo desto sera esleydo de los reyes de Françia un emperador santo al qual Dios dara poderio que sojudgara todas las tierras que son en Oriente e en Oçidente. E por todo el mundo este emperador rey sera de tanta santidad de quanta non fue ningund rey despues de Ihesu Christo. E este emperador, a honrra e serviçio de la corona de espinas de que Ihesu Christo fue coronado, non querra tomar corona de oro, e sera executor e conplira todos los mandamientos del dicho papa" (de Rocatallada, J., 1356, p. 323v) 
b) Pensamiento de regeneración del mundo: "e tribulaçiones que han de venir e contesçer antes que venga el anno de la encarrnaçion de mill e quatroçientos e setenta annos. E en aquel anno seran conplidas e acabadas todas las dichas tribulaçiones, e se començaran en el mundo a renovar e mejorar" (de Rocatallada, J., 1356, p. 322v)

c) Escatologías explicativas del fin del mundo y del tiempo:

“ca devedes saber que non puede mentir la escriptura que dize en el Libro de las Revelaçiones a los diez e nueve capitulos que fue tomada la bestia que salia de la mar que es el Antechristo de Oçidente e los sus falsos profetas, que seran metidos en el pozo açendido de fuego e piedrasufre donde yaseran fasta mill annos. E despues de los mill annos sera suelto Satanas en el tienpo del postimero Antechristo. Antes que pasen los dichos mill annos Satanas sera ençerrado e preso en el pozo del abismo en tal guisa que non pueda engannar las gentes fasta que sean pasados los dichos mill annos" (de Rocatallada, J., 1356, p. 326v)

d) Mitologemas morales que instruyen al hombre por el buen camino: "la setima cosa es que muchos renegaran la fee catholica e se faran apostotas, en tal guisa que de los omes grave cosa sera de fallar uno que sea fiel en la fee e creençia dixo" (de Rocatallada, J., 1356, p. 321r). Y también: "el Papa e los cardenales, patriarcas, arçobispos e todas las otras presonas (sic) eclesiasticas han de ser reduçidas e torrnadas a un modo e manera de bivir muy acabado" (de Rocatallada, J., 1356, p. 321r).

e) Mitologemas soteriológicos referentes a la salvación de los hombres gracias a la intermediación de Dios o por intermediación del Mesías (Lozano Escribano, J. y Anaya Acebes, L., 2002, p. 58-59): “e antes la tierra se sumira e el çielo peresçera, que non dexarse de conplir e fazerse lo que dixo Ihesus Christo" (de Rocatallada, J., 1356, p. 318v), y “onde si los perlados de la Santa Iglesia andudiesen por el mundo con muchos omes de cavallo e con grandes onrras e ponpas para pedricar e convertir a los moros e a los infieles" (de Rocatallada, J., 1356, p. 319r)

En definitiva, el apocaliptismo es un género literario, pero también una corriente de pensamiento. Estas dos cuestiones se unen en los siguientes elementos:

a) Lenguaje apocalíptico, que introduce simbolismos numéricos o referencias a aves, bestias o dragones. Es decir, recurre a la psedonimia (grandes narraciones donde se van introduciendo símbolos críticos). Asegura J. Rocatallada:

"La segunda maravilla es que antes que lleguemos al anno de mill e quatroçientos e sesenta e çinco annos que aparesçera publicamente en tierra de Oriente un Antichristo, e los diçipulos verrnan en tierra de Iherusalem e pedricaran publicamente por convertir la gente a la creençia deste Antechristo, e mostraran e faran grandes maravillas e sennales por poderio del Antechristo e del espiritu malino" (de Rocatallada, J., 1356, p. 320v)

b) Argumento escatológico. "E tribulaçiones que han de venir e contesçer antes que venga el anno de la encarrnaçion de mill e quatroçientos e setenta annos. E en aquel anno seran conplidas e acabadas todas las dichas tribulaçiones, e se començaran en el mundo a renovar e mejorar” (1356, p. 322v), pronostica Rocatallada.

c) Elementos proféticos (Lozano Escribano, J. y Anaya Acebes, L., 2002, p. 60). Se produce para los eclesiásticos: "las presonas eclesiasticas muchas peresçeran por manos de los crueles christianos e por muerte con espada, e otros peresçeran por muchas e desordenadas tribulaçiones e torrmentos dellos por fanbre e otros por grandes enfermedades, e otros por muchos torrmetos e espantos" (de Rocatallada, J., 1356, p. 319v). Pero también para los infieles en general: "devedes saber que los dichos rectores e perlados antes que lleguemos al anno de mill e quatroçientos e setenta annos, queriendo o non queriendo, por muchos torrmentos e grandes tribulaçiones, seran torrnados a la manera de bivir de los apostoles, e por esto podran ensennar a los infieles asi commo pertenesçe" (de Rocatallada, J., 1356, p. 310v). 


\section{Los estratos De LO POLÍtico en J. Rocatallada}

Para trabajar con esta historia política, así como todo lo relativo al texto en sus estratos real/ficcional, recurriremos al análisis de eventos, tanto en su dimensión real como "maravillosa". En esa exploración con los acontecimientos, debemos tener en cuenta que estos están insertados en el relato histórico a partir de la idea medieval de que Dios es el último responsable de lo que sucede en el mundo y a los hombres. Por tanto, el suceso en el mundo cristiano no tiene autonomía, está a disposición de un relato preconcebido tanto en el desarrollo contextual como en su tiempo, que es, por un lado, el tiempo lineal que lleva al apocalipsis. Y, por otro lado, el tiempo circular que asfixia los hechos alrededor del tiempo litúrgico y social (de los campesinos y señores). Todos los acontecimientos que forman y de los que forman parte están ordenados en esa disposición. Es decir, Rocatallada desarrolla una "historia política" propia de su época donde figuran elementos reales e imaginarios. Veamos los diferentes estratos.

En cuanto al estrato de lo real, J. Rocatallada nos proporciona una interesante reflexión:

a) Lo "real vivido", que conlleva un tiempo circular (eclesiástico y social) y lineal (Salvación, Paraíso y Juicio Final). Hay pasajes que contienen los diferentes tiempos: "Onde si los perlados (sic) de la Santa Iglesia andudiesen (sic) por el mundo con muchos omes de cavallo e con grandes onrras e ponpas para pedricar e convertir a los moros e a los infieles" e (Rocatallada, J., 1356, p. 319r).

b) Lo real crítico. El texto muestra muchos pasajes que muestran disconformidad con el tiempo vivido. El primero sería: "las presonas eclesiasticas muchas peresçeran por manos de los crueles? christianos e por muerte con espada, e otros peresçeran por muchas e desordenadas tribulaçiones e torrmentos dellos por fanbre e otros por grandes enfermedades, e otros por muchos torrmetos e espantos" (de Rocatallada, J., 1356, p. 319v). Y el segundo: "e el monesterio de Sant Françisco de la dicha villa de aqui a poco tienpo sera desanparado e quedara del todo desierto, ca por çierto a la dicha villa e monesterio avenira todo esto si non quisieren fazer penitencia de los sus pecados" (de Rocatallada, J., 1356, p. 325r).

c) Lo "real escrito", que es el relato que crea esa imagen e imaginario escatológicos:

"devedes saber que los dichos rectores e perlados antes que lleguemos al anno de mill e quatroçientos e setenta annos, queriendo o non queriendo, por muchos torrmentos e grandes tribulaçiones, seran torrnados a la manera de bivir de los apostoles, e por esto podran ensennar a los infieles asi commo pertenesçe" (de Rocatallada, J., 1356, p. 319v)

d) Lo "real recordado", que es todo el reflejo de lecturas y memorias orales: "e otrosi muchos dotores, sabidores, filosofos e estrologos se travajaron de fablar de los tienpos e de las tribulaçiones sobredichas, de las quales en aqueste libro testigos non aduxo" (de Rocatallada, J., 1356, p. 328r).

Ahora vamos con lo real-histórico. En términos de historiografía contemporánea podríamos definir a J. Rocatallada como un historiador de lo intelectual o de lo político. De tal forma, hace un recuento de la historia política:

Así, hace una explicación global a la situación en el mundo: "E porque en Africa e en Ungria los pedricadores (sic) e ensenadores de la fee, e asi mesmo en la mayor parte del mundo" (de Rocatallada, J., 1356, p. $318 \mathrm{v}$ ) y en "terçero remedio es parar mientes a las sennales que han de venir, asi commo en el movimiento de la tierra que sera fecho en el anno de la encarnaçion de mill e quatro çientos e sesenta e çinco annos. E en Alemanna e en Portogal e en Lisbona e en Sevilla e en Gascuenna” (de Rocatallada, J., 1356, p. 326r).

La historia política eclesiástica y su futuro también entran en juego en J. Rocatallada:

"uno destos dos frayles ha de ser papa e vicario de Ihesu Christo, e el otro sera cardenal, e estos dos pobres vestidos de sacos e çennidos de cuerda lidiaran e moveran batalla contra aquel bravo e grave dragon e serpiente antigua que es el Antichristo de Roma, e seran vençedores e non sera vençidos" (de Rocatallada, J., 1356, p. 323r). 
El cisma de Aviñón es parada obligada en la situación política que pertenece al momento del siglo XIV cuando se escribió el texto: "el quarto capitulo es en commo devisa e demuestra en aquel tienpo e en aquel anno e en aquel dia la corte de Roma ha de fuyr e se ha de partir de la çibdad pecatriz de Avinnon" (de Rocatallada, J., 1356, p. 320r).

Y no faltan las referencias a la importancia de España en ese momento, puesto que es fundamento esencial en las preocupaciones de Rocatallada:

"otrosi sabed que en estos quatro annos que han de pasar que han de pasar antes de mill e quatroçientos e setenta se ordena e apresta el mundo para las cosas que han de contesçer en los dichos çinco annos que devisados son en el dicho quinto capitulo. E para las batallas que han de ser en Espanna e en Italia e para los peligros grandes e terribles que los infieles han de cometer contra los pueblos de los christianos en las batallas de Espanna, uno de los reyes ha de levar mejoria e ser vençedor, el qual tanto creçe ya e sera ensalçado que avra poder de perseguir e estroyr el pueblo de los moros, e espeçialmente en tierra de Africa” (de Rocatallada, J., 1356, p. 321v)

Las guerras o las tiranías tienen referencias constantes en la obra: "El quinseno capitulo nos es demostrado e declarado en commo muchas çibdades del mundo onrradas han de ser perseguidas" (de Rocatallada, J., 1356, p. 325r)

De todas formas, su relato político es, en ocasiones, rectificado. J. Rocatallada trata de buscar puntos medios y de "conclusión positiva" en las argumentaciones. En un primer momento denuncia, pero siempre busca un punto de encuentro y de compensación: "despues de las tribulaçiones que se agoora comiençan e han de recreçer de grado en grado, ellas conplidas e pasadas todo el mundo asi judios commo moros, griegos, tartaros e turcos, todos han de ser convertidos a la fee catholica e torrnados a mandamiento e obedençia de Santa Iglesia" (de Rocatallada, J., 1356, p. 318v)

En todo caso siempre deja una posibilidad de cambio:

"verrnan los moros e infieles turcos e tartaros barvaros griegos para destruyr e perseguir el pueblo de los christianos, e asi que estragaran a Ytalia e a Lonbardia, e arada? la tierra de Ungria e Colonnia e grand parte de Alemanna. E esto durara por quarenta e dos meses, e por ninguna arte non podra ser fecha paz nin tregua por que se enbargue de non benir las cosas dichas en el dicho quinto capitulo" (de Rocatallada, J., 1356, p. 321v)

Esto en relación con lo político, pero sucede lo mismo con lo eclesiástico: "que quiera reobrar e reparar la su Santa Iglesia e acreçentar la fee por buenos pedricadores e ensennadores, la qual peresçia por maldad e negligençia de los rectores de la Santa Iglesia” (de Rocatallada, J., 1356, p. 318v).

J. Rocatallada muestra una crítica importante con el mundo que vive tanto en lo laico como en lo eclesiástico:

“sobre la cleresia sera fecha e complida la dicha muerte e persecuçion, por que la mayor parte della es enduresçida e levantada por soberbia e por pecado de avariçia e de riqueza e por gloria de los plaseres, en tanto e tal guysa que muchos dellos antes querrian e querran obligarse a las penas del Infierrno que torrnar a bivir en pobreza nin en la vida de los apóstoles" (de Rocatallada, J., 1356, p. 319v)

Muestra un ensalzamiento de los reyes franceses: "Onde sabed que en ensalçamiento del rey Françia e del poderio de los françeses que se naturalmente començo en el anno que este libro fue fecho e creçe de cada dia que ha de contesçer asi, que antes que la iglesia fuya de ay de Avinon e antes que venga el Antechristo ha de ser abaxada la sobervia e valentia de Françia” (de Rocatallada, J., 1356, p. 321r)

En cuanto a los musulmanes, siempre apela a su destrucción: "en paz e destruyda la seta de Mahoma, e en estos annos pasaran a tierra de Ungria e de Greçia e sojudgarla han, e los tartaros e turcos e griegos todos seran torrnados a la obedençia de Santa Iglesia” (de Rocatallada, J., 1356, p. 324r). Y más de lo mismo acontece con los judíos: "la quinta maravilla es que en aquellos çinco annos se esforçaran los judios e demandaran e seguiran el Antechristo diziendo que aquel es su mexias" (de Rocatallada, J., 1356, p. 321r).

En otro sentido, el relato de J. Rocatallada, ofrece toda una serie de pasajes que hacen referencia a lo ficcional, lo que J. Le Goff (1985) denomina como "maravilloso", y que lo utiliza J. Rocatallada para 
ofrecer una visión "completiva" del mundo, para buscar espacios de "compensación" de la dura cotidianidad medieval, así como para ejercer la crítica al mundo y a la Iglesia del momento. Al mismo tiempo, es un recurso narrativo para buscar una evasión de la realidad de la vida medieval (peste, malas cosechas, guerras, hambrunas, etc.). Según J. Le Goff lo maravilloso se opone a lo fantástico (lo ilusorio), lo prodigioso (el profetismo) y lo extraño (lo sobrenatural). Lo maravilloso para J. Le Goff se caracteriza por la rareza y el asombro que suscita. ${ }^{1}$ Y por la posibilidad de disfrutar de los atractivos de este mundo. ${ }^{2}$

Veamos, pues, el estrato asociado a pasajes maravillosos.

a) Sobre la presencia de seres maravillosos: "e quando las dos bestias que el Antechristo uviere e Satanas fuere atado en fondo de los abismos, onde yasera preso por mill annos asi commo dize Sant Iohan en el viçesimo capitulo del Libro de las Revelaçiones” (de Rocatallada, J., 1356, p. 326r).

b) En relación con lo maravilloso-cotidiano: "esta osadia e atrevimiento de las alimanias de pequenna fuerça demuestra e signefica que los pueblos e la gente menudos de pequenno valor seran de tanto esfuerço e levantarse han contra los prinçipes e fijosdalgo e poderosos, e pereçeran e descaeran de sus sennorios e gloria, e seran privados de sus riquesas e de sus onrras" (de Rocatallada, J., 1356, p. 320v).

c) Sobre lo maravilloso-personal: "el primer remedio es que dize Sant Mateo en el evangelio a los XXIIII capitulos, donde dize e demuestra que non queramos ser enganados creyendo en cosa que diga nin faga el Antechristo nin ninguno que sea que su parte tenga" (de Rocatallada, J., 1356, p. 325v).

d) En el texto es importante lo maravilloso político. Hay referencias al Anticristo: "hay una construcción. En el deçimo capitulo fabla en commo dos maravillosos profetas han de venir aparesçer? de los quales Sant Juan fabla en el deçimo capitulo en el sobredich que han de lidiar e contradezir al Antechristo de Roma que es figurado por aquella bestia que salia de la mar o libro" (de Rocatallada, J., 1356, p. 322v). También están relacionados con el orden eclesiástico: "las presonas eclesiasticas muchas peresçeran por manos de los crueles? christianos e por muerte con espada, e otros peresçeran por muchas e desordenadas tribulaçiones e torrmentos dellos por fanbre e otros por grandes enfermedades, e otros por muchos torrmetos (sic) e espantos" (de Rocatallada, J., 1356, p. 319v).

Estas imágenes ponen de manifiesto las relaciones entre lo real y lo ideal, que en buena medida complementa la relación realidad/representación. En otro sentido, tradicionalmente se ha considerado que en el texto de J. Rocatallada no destacan los episodios de visiones y maravillas. Lo maravilloso aparece en ocasiones vinculado a la naturaleza, que a su vez está relacionado con anuncios catastróficos.

Pasando de una matriz descriptiva a otra analítica, veamos lo maravilloso como una forma "completiva" del mundo y como un elemento de disidencia y de una forma camuflada de crítica.

En cuanto a lo maravilloso-completivo del mundo: "Esta osadia e atrevimiento de las alimanias de pequenna fuerça demuestra e signefica (sic) que los pueblos e la gente menudos de pequenno valor seran de tanto esfuerço e levantarse han contra los prinçipes e fijosdalgo e poderosos, e pereçeran e descaeran de sus sennorios e gloria, e seran privados de sus riquesas e de sus onrras" (de Rocatallada, J., 1356, p. 320v).

Por otro lado, tenemos lo maravilloso como profecía crítica para buscar un relato de perfección: "La quarta maravilla es que en los sobredichos çinco annos tanta mentira e engannos e falsedades regnnaran de los siervos e vasallos contra los sennores e entre si mismos, que bien aventurado sera aquel que servidor e serviçio e conpannero pudiere fallar" (de Rocatallada, J., 1356, p. 320v).

Dentro de lo maravilloso y lo visionario, J. Rocatallada ejerce la denuncia y la crítica de determinados acontecimientos que ocurren en su época.

a) Se hace eco de diferentes calamidades y situaciones sociales que se producen en el tiempo que concibe su relato: "La sesta cosa es que en las iglesias e altares e en los otros logares de oraçion por muchas partes del mundo seran destruydas e estragadas, e menguara e desfalleçera el sacrifiçio e serviçio de Dios" (de Rocatallada, J., 1356, p. 321r). 
b) Por supuesto que los males de la Iglesia de esa época están presentes. Lo maravilloso como esperanza y disidencia: "E otrosi sabed que este fuymiento ha de ser el çierto testigo e comienço de las cosas maravillosas que luego despues han de venir, que sabed que luego despues desto el papa e todos los perlados han de ser desapoderados de todas las posesiones e sennorios e bienes temporales" (de Rocatallada, J., 1356, p. 320r).

c) Más profunda es la crítica en la que hace referencia a la situación de la Iglesia, a la que afea su soberbia, avaricia y su tendencia al lucro en los diversos órdenes. Lo maravilloso como comienzo de la actividad de la Iglesia después de la llegada del Espíritu Santo, es decir como crítica de la sociedad y profecía positiva. Escribe Rocatallada (1356): "Estos seran de vestidos de vestiduras de sacos e de vestidura omildes, estos abran poderio de çerrrar los çielos que non llueva en el tienpo que ellos profetizaren, e avran poder de torrnar e convertir las aguas en sangre, e avran poder para ferir e atorrmentar la tierra e los moradores della cada que ellos quesieren, e para fazer miraglos e maravillas" (p. 323r)

d) Ofrece también un carácter reformista a partir de las propias maravillas:

“e continuamente seran en el mundo cosas nuevas e maravillosas, que seran estas primeramente las animalias de pequenna fuerça tomaran tanta osadia e atrevimiento que atrevidamente perseguiran e destruyran e mataron los leones e los osos e los lobos. E otrosi las aves pequennas, asi commo las merlas e los tordos, tomaran tanto atrevimiento que caçaran e tomaran los falcones e los açores e los gavilanes" (de Rocatallada, J., 1356, p. 320r)

\section{LA ESCATOLOGÍA EN RELACIÓN CON EL DISCURSO POLÍTICO}

El tiempo narrativo que nos ofrece J. Rocatallada en su texto es lineal, acotado desde el año 1460 hasta 1470. J. Rocatallada certifica el tiempo lineal con toda una serie de relaciones numéricas (referencias al número tres o siete que hacen referencia a la completitud de los tiempos. Así, apela a la idea de perfección y al concepto de espacio de perfección escatológico.

Podemos hablar, por tanto, de un "tiempo acontecido" lineal entre el 1460 y el 1470. Al mismo tiempo, también podemos referirnos a un "tiempo pensado" que responde a esa idea apocalíptica que llevaría a un espacio de perfección política con la llegada del nuevo milenio. Para combinar estas ideas, J. Rocatallada recurre a un tiempo circular que se construiría a partir de la idea de espera. El proceso de "espera" sería cíclico en el sentido de que aparecen y desparecen constantemente signos que hacen pensar en el fin de los tiempos, en la segunda venida de Cristo. Esa presencia cíclica completaría el tiempo "ciclo lineal" característico de la Edad Media. Un tiempo teórico creado por los monjes y por los teólogos que respondía a una matriz lineal y escatológica en el que a Dios le correspondería conducir a la humanidad hacia la salvación, y un tiempo circular cotidiano, vinculado a la vida política y eclesiástica de repetición constante.

Ese tiempo "ciclo lineal" alberga en su vientre otros tiempos, a saber:

a) Tiempo de las catástrofes y tiempo del fin o de la salvación: "el Papa e los cardenales, patriarcas, arçobispos e todas las otras presonas eclesiasticas han de ser reduçidas e torrnadas a un modo e manera de bivir muy acabado" (de Rocatallada, J., 1356, p. 320r).

b) Tiempo de paz y prosperidad: "e tribulaçiones que han de venir e contesçer antes que venga el anno de la encarrnaçion de mill e quatroçientos e setenta annos. E en aquel anno seran conplidas e acabadas todas las dichas tribulaçiones, e se començaran en el mundo a renovar e mejorar" (de Rocatallada, J., 1356, p. 322v).

c) Tiempo personal del autor con reflexiones personales y sucesos premonitorios: "fuesen pobres e vievieren en pobreza con grand razon a los tales perlados e pedricadores podrian" (de Rocatallada, J., 1356, p. 319r). Y, además: "otrosi seran atorrmentados de grande e grave pena e fanbre que en breve tienpo e çedo ha de venir e de otras pestilençias e tribulaçiones que son declaradas en el quinto 
capitulo deste libro. Otrosi avran de ser apremiados e emendados de los sus exçesos e torrnados a dicha e justa manera de bevir" (de Rocatallada, J., 1356, p. 324v).

d) Tiempo profético: "devedes saber que los dichos rectores e perlados antes que lleguemos al anno de mill e quatroçientos e setenta annos, queriendo o non queriendo, por muchos torrmentos e grandes tribulaçiones, seran torrnados a la manera de bivir de los apostoles, e por esto podran ensennar a los infieles asi commo pertenesçe”" (de Rocatallada, J., 1356, p. 319v).

e) Tiempo de aparición de prodigios y calamidades: "la grand pestilençia que han de foyr a los montes e esconderse asi commo las palomas en los penedos escondidos, e que esta tribulaçion durara çinco annos. Por ende que los que son cuerdos e sabios deven fazer provision en los montes e en las cuevas, e en los lograres çiertos e escondidos poner provision de havas e de otras legunbres, e de carrnes" (de Rocatallada, J., 1356, p. 325v)

Sobre esto hay más ejemplos, como: "onde seed çiertos e non dubdedes que sin descanso arrebatadamente han de venir e recreçer tantas tribulaçiones por todo el mundo en tanto grado que en el anno de la encarnaçion de mill e quatroçientos e sesenta e dos annos a quinse dias del mes de julio fuyran los cardenales con espanto e temor de la grand tribulaçion” (de Rocatallada, J., 1356, p. 320r).

f) El tiempo lineal: "el quinto capitulo es en commo son declaradas e divulgadas las grandes maravillas e espantos que han de contesçer e de venir en el mundo, e esto desde el anno de la encarrnaçion de mill e quatroçientos e sesenta annos fasta que esta conplido el anno de la encarrnaçion de mill e quatroçientos e sesenta e çinco annos" (de Rocatallada, J., 1356, p. 320r).

\section{El discurso político al Servicio del Milenarismo y Del Fin DeL MUNDo}

El tiempo que ofrece J. Rocatallada en su relato tanto práctico como teórico es lineal en el sentido escatológico, es decir, está construido desde un inicio hacia un fin con el hilo conductor de la idea de la reordenación de los eclesiásticos para alcanzar el fin del mundo y la llegada del milenarismo. Con tal marco, nos encontramos con referencias al principio de la historia. Entre la idea de principio y la de fin, encontramos la construcción de la linealidad cuando J. Rocatallada hace referencia a que él escribe señalando que no es un profeta. Las referencias a la linealidad son constantes. Lo vemos, por ejemplo, en:

"E esto mas entended que contesçera a muchas villas e logares e çibdades que peresçeran en la tribulaçion grande e grave que çedo ha de venir. Primeramente por grandes torrmentos e movimientos de la tierra quales non fueron desde el comienço del mundo, e sera fecho desde el anno de la encarrnaçion de mill e quatroçientos e sesenta e entre el anno de sesenta e çinco, de los quales movimientos de la tierra pasaron ya dellos pocos en el anno de la encarrnaçion de mill e quatroçientos e çinquenta e cinco" (de Rocatallada, J., 1356, p. 325r)

La otra matriz temporal medieval, la circular, también está presente. Con relación al tiempo circular tenemos que matizar que J. Rocatallada escribe desde el propio tiempo franciscano que está vinculado con el tiempo circular de la liturgia y de la vida eclesiástica, que representan una idea circular del mundo real, puesto que se repite cada vez que se realizan las eucaristías o las fiestas litúrgicas. En todo ello se hace presente lo ausente de forma constante.

La concepción del tiempo en J. Rocatallada tiene también su vinculación con el espacio. El espacio que construye el relato "curvilineal" enmarca y acota la salvación sobre el espacio que la alberga, que es el futuro liberado de todos los males. Una variante del tiempo lineal es la escatología, que podemos desgajar en diferentes apartados relativos a la idea de "fin del mundo" y al milenarismo

En cuanto al fin del mundo, J. Rocatallada hace diferentes menciones:

a) Lo maravilloso para referirse a la profecía previa al fin del mundo:

"la terçera maravilla es que en los dichos çinco annos avra en el mundo tantas de tenpestades e espantos del çielo que sera maravilla. E otrosi seran tantas enfermedades e postemas e es[...]s e otras 
dolençias arrebatadas que sin detemiento han de matar las gentes, e esto han mas de ser que el omme puede cuydar, e han de ser aguas de luvias mas que nunca fueron desde el tienpo de Noe aca. E otrosi han de ser grandes fanbres e gran mengua de viandas qual aun non fue vista. En tal guisa que por las dichas tribulaçiones e afliçiones e pestilençias han de morir e peresçer la mayor parte desta generaçion e gente mala desconoscida a Dios que agora bive” (de Rocatallada, J., 1356, p. 320v).

b) El fin del mundo como destrucción:

\footnotetext{
"antes que venga el anno de la encarrnaçion de mill e quatroçientos e sesenta e çinco annos los prinçipes e los sennores e los otros pueblos se levantaran e se ensanaran contra los clerigos e presonas eclesiasticas aborreçendo la su sobejana ponpa e grand baxedad de lo de la Iglesia tenporal e los bienes del mundo arrebatadamente sin detenerse levantaran los prinçipes e los pueblos, e los tomaran e los tiraran los sennorios e ducados e condados, e todo sennorio e tierra e todo patremonio, fasta que la dicha cleresia sea torrnada a bivir en pobreza e en umilldat e en aquella" (de Rocatallada, J., 1356, p. 321v)

c) Vínculo del fin con el Anticristo:
}

"el otavo capitulo fabla del Antechristo de Roma que ha de venir para aflegir toda la Santa Fee e cleresia. E este Antechristo paresçera publicamente en el Imperio de Roma desdel anno de la encarrnaçion de mill e quatroçientos e sesenta e dos annos poco mas o menos, e non tardara su persecuçion que non venga fasta el anno de mill e quatroçientos e sesenta e çinco annos. E la persecuçion del dicho Antechristo durara quarenta e dos meses. E yo digo que Antechristo es es aquella bestia cruel" (de Rocatallada, J., 1356, p. 321v)

Por otro lado, el «Vade Mecum in Tribulatione» nos muestra elementos milenaristas. El concepto de milenarismo, definido por Juan en el Apocalipsis, procede la interpretación que Pedro hace en la epístola II, 3, 8, según la cual: "un día es como mil años, y mil años como un día" (Lozano Escribano, J. y Anaya Acebes, L., 2002, pp. 117-118). La cifra de mil carece de todo significado desde el punto de los ciclos naturales. En la teología cristiana clásica el milenio no designa un periodo de la historia humana sino un reino de felicidad que debe durar mil años, desde el retorno de Cristo hasta el día del Juicio Final. El advenimiento de ese milenio comienza por el apocalipsis o fin del mundo y es importante saber cuándo va a llegar para prepararse (Baumgartner, F. J., 1999).

El milenarismo es una estrategia del hombre para procurarse seguridad psicológica frente a la indeterminación del futuro. El concepto de milenio vendría justificado por una estrategia para buscar una regularidad numérica que libere así de incertidumbres. El milenarismo surge de la vinculación del apocalipticismo general con una teoría numérica concreta, la del fin del mundo que se avecina. El milenarismo, es arbitrario y se caracteriza por la creencia de que el número mil es el fundamento oculto para comprender tanto el orden natural como la salvación de las almas. El milenio nació fundamentalmente como una idea en el campo de la escatología de las visiones futuristas relativas a un fin beatífico del tiempo, contenidas en los dos grandes libros apocalípticos de la Biblia, el de Daniel en el Antiguo Testamento y el Apocalipsis de Juan en el Nuevo Testamento; esto puede verse en E. Weber (1999). A partir de esas ideas del fin del mundo, el cristianismo elaboró su propio mitologema, según el cual el reinado de Cristo sería una época beatífica futura que duraría mil años y acabaría con una batalla definitiva y un juicio final, que puede verse en B. E. Whalen (2009).

Podemos señalar que el milenarismo se mueve en un carácter metahistórico trasladado hacia un futuro donde Dios consumará la salvación de los hombres;

a) Como es metahistórico tiene que ser revelado por Dios: "E uno destos dos frayles ha de ser papa e vicario de Ihesu Christo, e el otro sera cardenal, e estos dos pobres vestidos de sacos e çennidos de cuerda lidiaran e moveran batalla contra aquel bravo e grave dragon e serpiente antigua que es el Antichristo de Roma, e seran vençedores e non sera vençidos” (de Rocatallada, J., 1356, p. 323r).

b) Hay profetas apocalípticos que son personajes arrebatados al cielo; su finalidad es parenética, trata de amonestar y preparar al creyente para hacer frente a las situaciones de crisis que se avecinan. "El 
terçero capitulo nos demuestra e ensenna grandes tribulaçiones e afliaçiones que ninguno non podria pensar que han de benir sobre toda la cleresia" (de Rocatallada, J., 1356, p. 319v).

c) Su lenguaje pesenta lo humano como divino:

"La segunda maravilla es que antes que lleguemos al anno de mill e quatroçientos e sesenta e çinco annos que aparesçera publicamente en tierra de Oriente un Antichristo, e los diçipulos verrnan en tierra de Iherusalem e pedricaran publicamente por convertir la gente a la creençia deste Antechristo, e mostraran e faran grandes maravillas e sennales por poderio del Antechristo e del espiritu malino" (de Rocatallada, J., 1356, p. 320v)

Respecto al milenarismo en sí mismo tenemos los siguientes pasajes:

a) El milinerismo en relación al Anticristo:

"E despues deste tienpo acabado seteçientos annos a las vegadas seran batallas e fanbres e otras pestilençias muchas, enpero non podran durar mucho. E cuando llega el tienpo de los mill annos conplidos quando viniere el postrimero Antechristo sera suelto Satanas de la carçel en que fue puesto, e seran estonçes en el mundo tantos errores e tribulaçiones quantas en Asi son juntados setenta e ocho annos e medio con los sobre dichos mill e trezientos e noventa de que sobre dicho es, fasen por todos mill e quatroçientos e sesenta e ocho annos e medio. E asi paresçe que la dicha tribulaçion del Antechristo de que ya en este libro avemos dicho sera conplida e acaba quando fuere conplido el cuento de los annos de la encarrnaçion de mill e quatroçentos e sesenta e ocho annos e medio. el mundo nunca fueron”. (de Rocatallada, J., 1356, p. 327r)

b) En relación con el apocalipsis:

"la segunda cosas es que ha de contesçer dize Sant Iohan en el sobredicho libro e capitulo, en la dicha batalla pareçera un angel del çielo que traera en su mano una grand cadena con que prendera a Satanas, e lo atara e lo lançara en el pozo del abismo e lo terrna encarçelado por mill annos, asi commo ya declarado es. E por que el dicho Satanas sera atado e preso e non podra engannar nin desvariar las gentes fasta que sean conplidos los dichos mill annos. Por ende aquellos mill annos bivira el mundo en paz e en sosiego e seguramente" (de Rocatallada, J., 1356, p. 327r)

c) Explicación del milenarismo en sí mismo:

"ca devedes saber que non puede mentir la escriptura que dize en el Libro de las Revelaçiones a los diez e nueve capitulos que fue tomada la bestia que salia de la mar que es el Antechristo de Oçidente e los sus falsos profetas, que seran metidos en el pozo açendido de fuego e piedrasufre donde yaseran fasta mill annos. E despues de los mill annos sera suelto Satanas en el tienpo del postimero Antechristo. Antes que pasen los dichos mill annos Satanas sera ençerrado e preso en el pozo del abismo en tal guisa que non pueda engannar las gentes fasta que sean pasados los dichos mill annos" (de Rocatallada, J., 1356, p. 326v)

d) El milenarismo como anuncio de tiempo de futuro con fin: " 2 n el deçimo otavo capitulo nos declara e demuestra en commo el mundo ha de durar mill annos en paz e sosiego" (de Rocatallada, J., 1356, p. 326v).

e) También cita a todos los elementos milenaristas sobre los que construye su relato Rocatallada. Así, satanás, el anticristo, el propio libro del «Vade Mecum», el evangelio de San Juan y los mil años:

“e este es aquel angel de que fabla Sant Juan en el libro de la Revelaçiones a los veynte capitulos, e que ha poder e tiene cadena grande en la su mano para ensennorearse de Satanas e para lo liar e prender e meterlo en la baxeza de los abismos e de las tiniebras, e yra preso e non saldra nin sera suelto fasta que sean conplidos doss mill annos. Estonçe sera suelto para ayudar e aprovechar al postrimero Antechristo asi commo en el tienpo de agora sera suelto para ayudar e ensennar al Antechristo de Roma de quien fabla el otavo capitulo deste libro" (de Rocatallada, J., 1356, p. 322v)

\section{Conclusiones}

Por tanto, escatología, apocaliptismo, milenarismo y fin del mundo son conceptos que están presentes en el libro de J. Rocatallada que se compone para el siglo XIV y se moderniza para el siglo XV castellano en esta versión ovetense. 
a) Hay un gran número de señales maravillosas y de destrucción entre los años que abarca el texto que pueden ser entendidas como comunicación de Dios con los hombres y síntomas del acercamiento del fin del mundo (Schaefer, B. E., 2003); con lo que se infiere ante un texto milenarista y apocalíptico.

b) La espera escatológica se concentra únicamente alrededor del año 1460-70 y lo que sucede después es un alegato franciscano-joaquinita de la edad del espíritu.

c) las especulaciones sobre el discurso apocalíptico político están matizadas por el hecho de que los intelectuales europeos pueden verse afectados por su mentalidad laica y/o agnóstica, que les hace no entender el sentido religioso atribuido a la mayoría de los acontecimientos que los testigos de aquellos tiempos consideraban dignos de ser relatados (Rousset, P., 1956; 1951; Flori, J. 2010, pp. 315-321)

d) Los temores, las angustias y la obsesión con el fin de los tiempos ha sido realizada por clérigos, príncipes y por el pueblo (Gouguenheim, S., 1999, pp. 55-56), pero es algo difícil de manejar y explicar en su conjunto, por eso se ha desviado siempre a una cuestión de que eran cosas de élites intelectuales.

e) El apocalipsis de San Juan y muchos textos son fundamentales para entender a J. Rocatallada, puesto que van calcetando lo que será la idea de perfección que alumbrará al final de los tiempos, pese al ejercicio de coerción que realizaban los textos de San Agustín.

f) El «Vade Macum in Tribulatione» también está conformado por acontecimientos reales y maravillosos que llevan a la conformación de realidades compensatorias, optimistas y de perfección.

g) El discurso político apocalíptico significa ordenar la escatología en una temporalidad ciclo lineal con el fin de alcanzar la salvación. El tiempo circular sería el tiempo de espera, con idas y venidas sobre el fin del mundo. Y el tiempo lineal sería la propia introducción de un principio y un fin en la historia. La escatología es una forma de proyectar el presente hacia el futuro

h) El relato historiográfico y la propia historia política de J. Rocatallada están al servicio de los diferentes presentes históricos y de los avatares políticos y de interés historiográfico de los diferentes historiadores. El sentido del relato histórico se construye desde cada generación que tiene sus propios intereses. Así el discurso político apocalíptico pasa de ser un mito creado por una serie de monjes a tener carácter performativo para conformar una sociedad "franciscana Joaquinita".

i) El discurso político de J. Rocatallada responde a una concepción teleológica, donde conocemos el resultado por anticipado según un plan previo. Eso lleva a la inmovilidad de la estructura narrativa y lleva a reflexionar sobre su significado, pero no sobre su sentido. La capacidad performativa de los textos puede existir en algunos casos, pero se obvia porque el texto tiene otra intencionalidad y está inscrito en un proceso de interacción con una audiencia.

j) Conviene revindicar el análisis dialógico en el que los elementos contradictorios de lo real coexisten antagónicamente unos con otros y encuentran en la persistencia de la contradicción su razón de ser y la plenitud de su sentido.

k) Estamos ante un debate historiográfico fundamentalmente francés, pero existen textos alejados de esa tradición histórica en los que hay elementos milenaristas. ¿ Tienen algo que aportar en el debate las historiografías y los textos periféricos?

Hemos visto como las temporalidades y los contextos ayudan a entender el texto de Glaber en coordenadas de lo maravilloso/real y del tiempo/espacio. Como consecuencia podemos concluir que la realidad política medieval escrita por J. Rocatallada está sostenida tanto en los pasajes maravillosos como en los reales, producto también de línea difusa que separa esas líneas en el mundo real medieval. Hemos evidenciado la importancia de lo maravilloso en el pensamiento de J. Rocatallada, al ser el reservorio que utiliza el autor para establecer pasajes críticos con la realidad que vive y también al representar el medio por el que introduce elementos de ficción. Todo en el marco de una temporalidad ciclo lineal escatológica con un fin apocalíptico. Eso no es óbice para que en algunos pasajes mezcle lo real/maravilloso. J. Rocatallada se manifiesta como un historiador tanto de lo político como de lo apocalíptico, en un ejercicio que ha llevado a la confusión de muchos de los especialistas. 
J. Rocatallada, además, escribe en primera persona en algunos pasajes y también nos deja algunos pasajes de su propio pensamiento. Y toda esa tarea la realiza desde el monasterio, que es el centro de la producción historiográfica medieval. Y escribe en el siglo XI, una época confusa en la que algunos especialistas hablan de que había un clima escatológico (para unos milenarista y para otros apocalíptico). Por tanto, trabaja desde un contexto histórico e historiográfico determinado donde tienen especial importancia la dimensión colectiva y un especial desarrollo autoral, como analiza J. Aurell (2013). Hemos defendido que la historiografía medieval tiene un valor como escritura histórica - el relato e historiografía han sido analizados por J. C. Conde (2000) - más allá de la distorsión que produce situarla como un eslabón imperfecto de una cadena de progreso que empezaría en el mundo clásico y que acabaría en el historicismo decimonónico. La historiografía medieval no es más que un campo para representar el mundo sistémico cristiano, donde se entremezcla historia, política, creencias, mentalidades, religión, etc.

J. Rocatallada en ocasiones se muestra ortodoxo, pero en esa ortodoxia nos inserta un cierto pensamiento milenarista. Sea cual sea la respuesta, este trabajo se ha alejado de esa matriz analítica y ha querido mantenerse en un campo intelectual de análisis alejado de los debates clásicos sobre esas cuestiones que ha suscitado, por tanto, se ha apartado de los diferentes "compromisos" que se han establecido al respecto. Hemos incidido en la cuestión de la temporalidad ciclo lineal y en el contexto maravilloso de su obra. Podemos preguntarnos: ¿el apocaliptismo le da sentido a la formación y legitimación de los reinos?, ¿J. Rocatallada mezcla futuro y apocalipsis en un final feliz?, ¿La realidad es un a priori del imaginario o una consecuencia de este?, ¿Este imaginario funciona de conector entre lo real y lo ideal?, ¿Una nueva relación social no puede surgir si no es pensada?

\section{ReFERENCIAS}

Aurell, J. (2013). La historiografía medieval: siglos IX-XV. En J. Aurell, C. Balmaceda, P. Burke y F. Soza, Comprender el pasado. Una historia de la escritura y el pensamiento histórico (pp. 95-142). Madrid: Akal.

Bignami-Odier, J. (1952). Études sur Jean de Roquetaillade (Johannes de Rupescissa). Paris: Vrin

Baumgartner, F. J. (1999). Longing for the End. A history of Millennialism in Western civilization. Palgrave: New York

Calderón Ortega, J. M. (1998). Álvaro de Luna: riqueza y poder en la Castilla del siglo XV. Madrid: Centro Universitario Ramón Carande.

Conde, J. C. (2000). Para una teoría de la historiografía en el ámbito universal de la Edad Media: notas sobre su caracterización como relato. En A. Wardi (ed.), Teoría y práctica de la historiografía hispánica medieval (pp. 167-192). Birminghan: The University of Birmingham Press.

Flori, J. (2010). El islam y el fin de los tiempos. La interpretación profética de las invasiones musulmanas en la cristiandad medieval. Madrid: Akal

Gómez Redondo, F. (2002). Historia de la prosa medieval castellana. Los orígenes del humanismo. El marco cultural de Enrique III y Juan II. Madrid: Cátedra.

Gouguenheim, S. (1999). Les Fausses Terreurs de l'an mil. Attente de la fin des tempos ou approfondissement de la foi?. Paris: Editions Picard.

Grupo de estudios Beato de Liebana (1978). Actas del Simposio para el Estudio de los Códices al Comentario del Apocalipsis del Beato de Liebana (3 vol.). Madrid: Joyas Bibliográficas.

Guadalajara Medina, J. (2004). El Anticristo en la España medieval. Madrid: Laberinto.

Guadalajara Medina, J. (1996). Las profecias del anticristo en la Edad Media. Madrid: Gredos.

Kaup, M. (2017). John of Rupescissa's Vade Mecum in Tribulacione (1356): A Late Medieval Eschatological Manual for the Forthcoming Thirteen Years of Horror and Hardship. Oxxon: Routledge.

Le Goff, J. (1985). Lo Maravilloso y lo cotidiano en el Occidente Medieval. Barcelona: Gedisa.

Le Goff, J. y Smitt, J. C. S. (eds.) (2003). Diccionario razonado del Occidente Medieval. Madrid: Akal. 
Lozano Escribano, J.y Anaya Acebes, L. (2002). Literatura apocaliptica cristiana (hasta el año 1000). Madrid: Ediciones Polifemo

Monsalvo Antón, J. M. (2010). Poder y cultura en la Castilla de Juan II: ambientes cortesanos, humanismo autóctono y discursos políticos. En L. E. Rodríguez-San Pedro Bezares y J. L. Polo Rodríguez (eds.). Salamanca y su Universidad en el primer Renacimiento: siglo XV (pp.15-92). Salamanca: Universidad Salamanca.

Ramires, F. (2012). Entre el silencio y el grito. Las manifestaciones emocionales como soporte del discurso historiográfico durante el reinado de Juan II de Castilla. Mirabilia: Revista Eletrônica de História Antiga e Medieval, 15, 56-73. Recuperado de: https://dialnet.unirioja.es/servlet/articulo?codigo $=4218157$

Reeves, M. (1969). The influence of Prophecy in the Latter Middle Ages. A Study of Joachimism. Oxford: Clarendon Press. de Rocatallada, J. (1356). Vade Mecum in Tribulacione. Biblioteca Capitular de Oviedo.

Rousset, P. (1956). Les sens du merveilleux à l'époque féodale. Le Moyen Áge, 72, 25-37.

Rousset, P. (1951). La conception de l'histoire a\# l'e\#poque fe\#odale. Paris: Presses universitaires de France.

Schaefer, B. E. (2003). The Astronomical Situation around the Year 1000. En R. Landes, A. Gow y D. C. Van Meter (eds.). The Apocalyptic Year 1000. Religious Expectation and Social Change, 950-1050 (pp. 329-337). New York: Oxford University Press.

Weber, E. (1999). Apocalypses et millénarismes. Prophéties, cultes et croyances millénaristes à travers les âges. Paris: Fayard

Whalen, B. E. (2009). Dominion of God. Christendom and Apocalipse in the Middle Ages. Cambridge: Harvard University Press

\section{Notas}

1 J. Le Goff entiende lo maravilloso como algo externo al hombre. Esta concepción se puede complementar con una visión de lo maravilloso como algo vinculado al propio individuo, como el resultado de un discurso interno e inconsciente (en términos lacanianos). Como consecuencia J. Le Goff hace una distinción entre lo maravilloso (real) y lo milagroso (sobrenatural), aunque sea difícil diferenciar ambos por interventores externos como el diablo y la magia. Ver J. Le Goff (1985) y J. Le Goff, y Smitt, J. C. S. (2003).

2 La Biblia era una fuente fundamental de lo maravilloso (también en Glaber). En el Nuevo Testamento destacó el Apocalipsis por su rica iconografía, sobre todo gracias a los manuscritos iluminados del Beato de Liébana y su influencia posterior. Paralelamente, también forma parte de lo maravilloso lo relativo a gigantes y enanos, todo el horizonte onírico y mítico del Occidente medieval, así como lo que viene de Oriente. En relación a esto último, destaca la leyenda de Gog y Magog, que se vincula con el fin de los tiempos y la llegada del Juicio Final y el Anticristo, además de las peregrinaciones. Ver Grupo de estudios Beato de Liebana (1978) y J. Le Goff, y Smitt, J. C. S. (2003). 